\title{
Medical Service Quality, Efficiency and Cost Control Effectiveness of Upgraded Case Payment in Rural China: A Retrospective Study
}

\author{
Ruibo He ${ }^{\circledR}$, Ting Ye, Jing Wang, Yan Zhang, Zhong Li®, Yadong Niu and Liang Zhang * \\ School of Medicine and Health Management, Huazhong University of Science and Technology, \\ Wuhan 430030, China; heruibo27@163.com (R.H.); yeting868@gmail.com (T.Y.); jingwang@hust.edu.cn (J.W.); \\ zhangyan1604@163.com (Y.Z.); lizhong@hust.edu.cn (Z.L.); nyadong@126.com (Y.N.) \\ * Correspondence: zhangliang@mails.tjmu.edu.cn; Tel.: +86-278-361-0982
}

Received: 21 November 2018; Accepted: 10 December 2018; Published: 13 December 2018

\begin{abstract}
Background: As the principal means of reimbursing medical institutions, the effects of case payment still need to be evaluated due to special environments and short exploration periods, especially in rural China. Methods: Xi County was chosen as the intervention group, with 36,104, 48,316, and 59,087 inpatients from the years 2011 to 2013, respectively. Huaibin County acted as the control group, with 33,073, 48,122, and 51,325 inpatients, respectively, from the same period. The inpatients' information was collected from local insurance agencies. After controlling for age, gender, institution level, season fixed effects, disease severity, and compensation type, the generalised additive models (GAMs) and difference-in-differences approach (DID) were used to measure the changing trends and policy net effects from two levels (the whole county level and each institution level) and three dimensions (cost, quality and efficiency). Results: At the whole-county level, the cost-related indicators of the intervention group showed downward trends compared to the control group. Total spending, reimbursement fee and out-of-pocket expense declined by $¥ 346.59(p<0.001), ¥ 105.39(p<0.001)$ and $¥ 241.2(p<0.001)$, respectively (the symbol $¥$ represents Chinese yuan). Actual compensation ratio, length of stay, and readmission rates exhibited ascending trends, with increases of $7 \%(p<0.001), 2.18$ days $(p<0.001)$, and $1.5 \%(p<0.001)$, respectively. The intervention group at county level hospital had greater length of stay reduction $(¥ 792.97 p<0.001)$ and readmission rate growth $(3.3 \% p<0.001)$ and lower reimbursement fee reduction $(¥ 150.16 p<0.001)$ and length of stay growth $(1.24$ days $p<0.001)$ than those at the township level. Conclusions: Upgraded case payment is more reasonable and suitable for rural areas than simple quota payment or cap payment. It has successfully curbed the growth of medical expenses, improved the efficiency of medical insurance fund utilisation, and alleviated patients' economic burden of disease. However, no positive effects on service quality and efficiency were observed. The increase in readmission rate and potential hidden dangers for primary health care institutions should be given attention.
\end{abstract}

Keywords: case payment; upgraded version; quality; efficiency; cost control; rural China

\section{Introduction}

With people's increasing awareness and need for accessible medical services, the prevalence of chronic diseases and the increasing trend of aging, among other factors, rising health expenditures have become a financial challenge for many countries and have increased patients' economic burden of disease. In 2016, about one-third of OECD (Organisation for Economic Cooperation and Development) countries' health expenditure accounted for $11 \%$ of their GDP (Gross Domestic Product). In the United 
States, the proportion of health expenditure is as high as $17.2 \%$ and may reach $19.6 \%$ in 2024 [1]. Although the figure in China is relatively low (5.5\%) [2], the government's health spending has risen from $¥ 177.9$ billion to $¥ 1.4$ trillion (the symbol $¥$ represents Chinese yuan), and per capita health expenses have increased from $¥ 748.8$ to $¥ 3351.7$ in the last 10 years [3]. Solving the problem of "kan bing nan, kan bing gui" ("getting medical care is difficult and expensive" [4]) has become an important issue in the new round of medical reform in China.

Given the information asymmetry and the absence of a cost control mechanism in the medical service system, the fee for service payment is more inclined to encourage supplier-induced demand, which is widely considered as the main reason for the inexorable growth of health expenditure [5]. Therefore, the shift from post-payment to pre-payment has become a critical strategy to control costs and improve the service efficiency of medical institutions. Case payment has gradually become the principal means of reimbursement in many developed countries since the introduction of diagnosis-related groups (DRGs) for U.S. Medicare patients in 1983 [6]. The core concept of case payment is to pre-set a fixed reimbursement amount to medical institutions. No compensation or partial compensation fee is given to suppliers if the actual expenses exceed this set quota [7], thereby constraining physicians' behaviour and prompting them to provide effective services within a reasonable range [8].

During implementation, case payment can be roughly divided into two versions. The elementary version sums the total medical expenses that cover the entire treatment process of a single disease [9], such as quota payment or cap payment $[10,11]$. This simple design has a low inclusion rate and high operating and managing costs because of the complexity of the disease. The sophisticated version calculates expenses according to patient groups who are clinically similar and have the same hospital resource utilisation by age, gender and diagnosis complications [12]. Examples of this version are DRGs in the United States and many European countries [13] and diagnosis procedure combination in Japan [14]. This design may induce physicians to treat patients whose costs are lower than the associated reimbursement, up-coding and shift the costs to other agencies. Both versions offer no incentives for the provider to assure service quality [6].

With universal health insurance coverage (which accounted for $96.3 \%$ of the population in 2014 [15]) and improvement of the compensation ratio, reimbursement fees have become the main source of revenue for medical institutions in China, which makes the payment method become the main strategy for regulating the behaviour of providers [16], in order to promote reasonable treatment, examinations, and drug utilization, and reduce patient burden of medical expenses. The Chinese government first issued a document of case payment in 2004, which required regions to implement pilot work [17]; the elementary version is mainly used in such implementations. After more than 10 years of exploration, the Chinese government began to promote case payment throughout the country in $2017[18,19]$. Existing studies have inferred that case payment is currently more ethically acceptable than fees for services in the context of China [20]. However, given that information systems and providers' coding capability are lagging, the sophisticated version cannot be implemented in rural areas at present [21].

Previous studies on the policy effects of case payment in rural China obtained contradictory conclusions on cost control because of the limitations of the elementary version [22,23]. Moreover, the effects on service quality and efficiency have not received equal attention, and the chosen method and indicators are not well justified; thus, any related findings are not persuasive [24]. Therefore, the present study selected a representative practice of the upgraded case payment model in $\mathrm{Xi}$ County $[25,26]$. This model can be regarded as a preliminary version of DRGs because it combines the clinical pathway and the severity of the disease. This study also evaluated its impacts on costs, quality and efficiency comprehensively. We presume that our study provides a reference value for case payment policy evaluation and areas where DRGs are not available. 


\section{Methods}

\subsection{Study Setting and Intervention Assignment}

Henan Province is a highly populous province and has the largest agricultural area in China [27]. Its resident population is 95.324 million, of which the rural population is 49.92 million or $51.5 \%$. Its per capita GDP reached $¥ 42,363$, ranking 20th among China’s 31 provinces and municipalities in 2016 . Xi County is part of Xinyang City, located $79 \mathrm{~km}$ from the downtown area, in southern Henan Province. Like other regions, the county has also been plagued by the rapid growth of medical expenditure. Hospitalisation expenses increased by 14.5\% every year from 2007 to 2010, according to a local health statistical report [28]. After summarising the experiences and shortcomings of the simple cap payment (low inclusion rate, high mutation rate, decline in medical quality) and with support from the World Bank's Rural Health Project [29], the local government initiated an upgraded case payment reform to alleviate the pressure of insurance funds in the latter half of 2011.

Even in situations where patients have the same disease, the costs may be different because of diverse conditions. Therefore, the local insurance department divided diseases into three categories according to their condition: simple (without complications, requiring conventional therapy only), complex (with complications that need to be treated), and extremely complex (the worst condition, requiring changes in diagnosis and therapy). Consequently, medical institutions combined the current service capability and treatment norm to perform "localisation" adjustment on the basis of the national clinical pathway. The final A/B/C path (corresponding to simple, complex, and extremely complex, respectively) was developed upon the approval of health administrative and insurance departments. The proportion of the three paths was set to 7:2:1 according to "the law of large numbers" [30] of disease incidence, and the C-path was not implemented at the township level.

To safeguard the effectiveness of the cost control measure, medical institutions and insurance department negotiated expenses based on the localised pathway. A certain profit margin was set to ensure the successful implementation of payment reform (the balance rate of township health centre was controlled at $15-20 \%$, and the balance rate of the county hospital was controlled within $15 \%$ ). Ultimately, the total spending, reimbursement fees and out-of-pocket expenses were determined for each path of the disease.

\subsection{Study Design and Variables}

The reform was implemented throughout Xi County in January 2012 (the exploratory stage took place in the second half of 2011, and the pathway inclusion rate was less than 5\%). Therefore, we used 2011 as the baseline period after excluding the few inpatients who were compensated through the upgraded model. To increase the reliability of the results, Huaibin County was chosen as the control group for three reasons. Firstly, its geographic proximity (see Figure 1) and population are similar to those of Xi County (Huaibin County was selected as the control group in previous studies on Xi County's health care delivery system) [27]. Secondly, the two counties have similar health resources, service capability, and patients' service utilisation habits (Table 1). Previous studies found that counties that did not implement payment reform had similar changes in their medical service-related indicators, which met the common trend assumption [16]. Thirdly, payment reform in Huaibin County is lacking (Huaibin began its global budget reform in 2014. Therefore, the time interval for this study is 2011 to 2013. Previously, inpatient service was still compensated by fee for service payment).

We intend to assess the effects from two levels (effects on the whole county and effects on different levels of medical institutions) and three dimensions (cost, quality and efficiency):

Although the county hospital and the township health centre can provide inpatient services, each of them has an explicit and relatively distinguished functional orientation. Township health centres play a pivotal role between village clinics and county hospitals and are responsible for primary care service of common diseases. County hospitals are the leaders of the three-tier health care delivery system in rural China and are committed to curative care for more complex diseases [31]. However, 
a trend exists in which patients seek higher-level medical services than what they actually need, which is one expression of irrational service utilisation [32-34]. The providers' characteristics and behaviours will undoubtedly affect patients' choice and health care outcomes [35]. Therefore, aside from evaluating the impact of reform on the overall county level, we also analysed medical institutions' responses at the county and township levels.

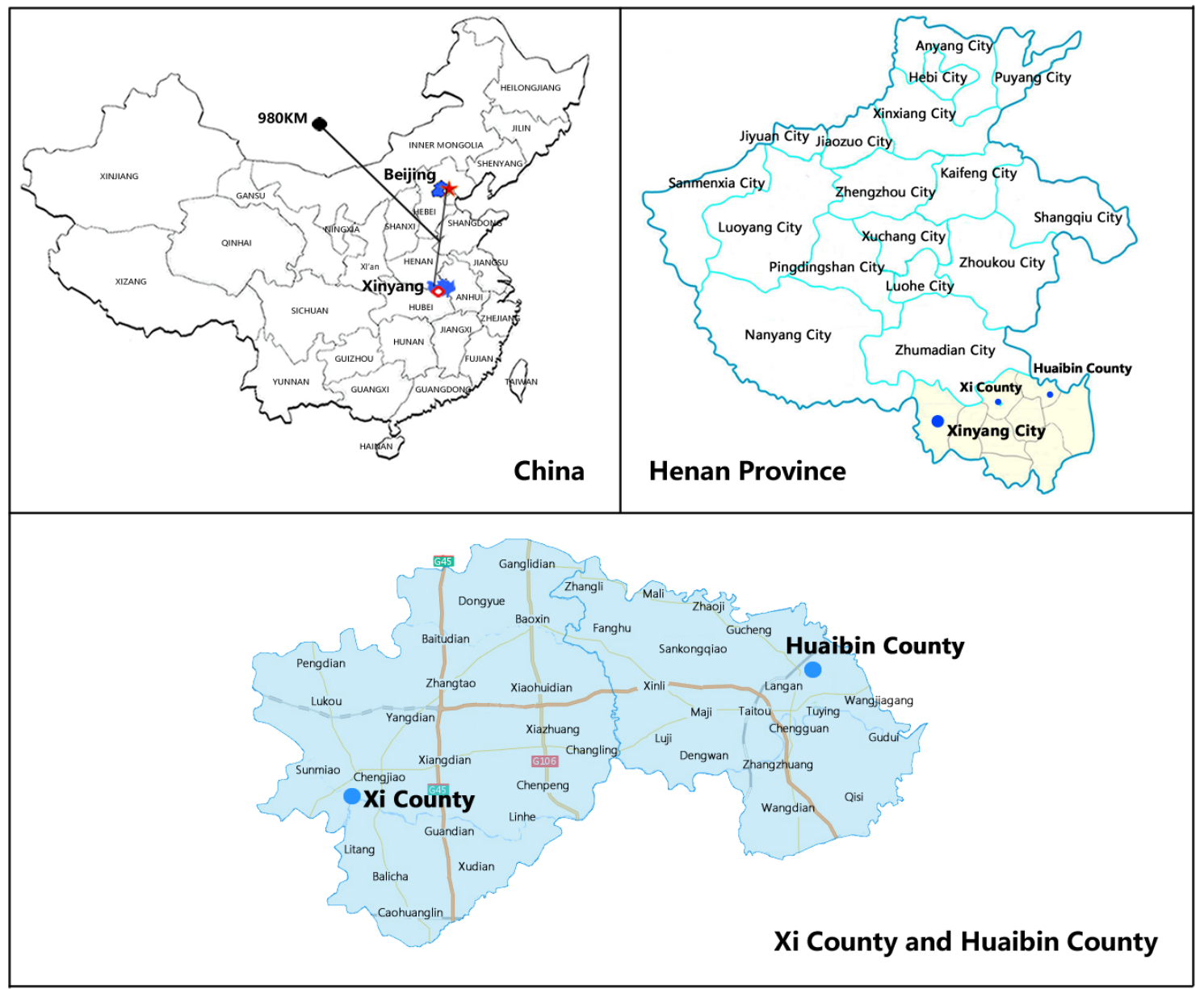

Figure 1. Locations of the $\mathrm{Xi}$ and Huaibin Counties in China and the Henan Province.

Table 1. Socioeconomic Indicators of Xi and Huaibin Counties in 2015.

\begin{tabular}{ccc}
\hline Indicators & Xi County & Huaibin County \\
\hline Location & Contiguous to Huaibin & Contiguous to Xi \\
Administrative districts & 21 & 19 \\
Urbanization rate (\%) & 35.7 & 36.2 \\
Permanent resident population (thousand) & 833.5 & 565.7 \\
Per capita annual income (yuan) & 13,235 & 12,946 \\
Number of county-level hospitals & 3 & 3 \\
Number of township hospitals & 20 & 19 \\
Number of hospital beds (per thousand population) & 2.05 & 2.38 \\
Number of practitioners (per thousand population) & 1.36 & 1.48 \\
Number of nurses (per thousand population) & 1.07 & 1.11 \\
\hline
\end{tabular}

The original purpose of case payment is to control costs, but its impact on efficiency and quality determines the achievement of its social goal. In the cost dimension, to make the result more specific, we analysed the effects on reimbursement fees, out-of-pocket expenses, and compensation ratio aside from total spending. The changes in length of stay before and after the intervention was compared 
to verify their effects on efficiency. The indicator of readmission within 30 days was determined to examine the effects on quality. All outcomes were calculated for every individual per inpatient visit [36]. The covariables contained individual traits (age, gender), level of medical institution, and disease severity (total spending was controlled to adjust the captured severity of illness. When the outcome variable was total spending, length of stay was controlled [36]), compensation type (whether or not patients were compensated by the upgraded version), year and season fixed effects. Data were obtained from the local health insurance agency and anonymised and de-identified before analysis.

\subsection{Statistical Analyses}

The difference-in-differences model (DID) is a scientific tool that is commonly used to evaluate intervention effects [37]. However, it can only show the final values and cannot reflect the changing trends of outcome variables during the intervention period. Therefore, we applied smoothing splines generated in generalised additive models (GAMs) [38] to indicate the effects between process and result.

GAMs, as semi-parametric extensions of generalised linear models, are applied to establish a relationship between the mean of the response variable and a "smoothed" function of the explanatory variables. Moreover, GAMs can deal with nonlinear and nonmonotonic relationships between the response and the set of explanatory variables with a link function [39]. Few studies have used GAMs in health policy evaluation and proved their validation $[40,41]$. In this part of the research, the "year" is the independent variable. After controlling the covariables, we constructed a smooth curve to observe the annual variation trends of the outcome variables of the intervention group and the control group at the whole county, county hospital, and township health centre levels.

To verify the trends reflected by the splines generated in GAMs and obtain more precise results, we adopted a DID using multivariate linear regressions, adjusted for covariables and time effects. In this part, three independent variables served as policy intervention indicators $(0=$ Huiabin County; $1=X \mathrm{i}$ County). Given the hysteresis effects, a post-policy indicator was assigned as 0 for the pre-intervention period (between 1 January 2011 and 31 December 2011) and 1 for the post-intervention period (between 1 January 2013 and 31 December 2013), and their interaction term. The price index of rural health care was used to calibrate all spending figures according to 2013 Chinese yuan values [42]. The software packages R (http:/ / www.R-project.org, The R Foundation, Mountain Ave, Murry Hill, NJ, USA) was used for all analyses. Results are reported with two-tailed p-values.

\subsection{Ethics Statement}

The research methods and investigation tools in this study were approved by the Ethics Committee of Tongji Medical College, Huazhong University of Science and Technology (IORG No: IORG0003571).

\section{Results}

\subsection{Study Sample Characteristics}

For consistency with DID analysis, Table 2 displays the information of the two groups in 2011 and 2013. The number of inpatients (male and female) in the intervention group was higher than that in the control group. The number of male inpatients was lower than that of female patients in both counties before and after the intervention. The 35-64 year age group was the main component, and the group over 65 years old showed an escalating trend. At the baseline, the mean values of total spending, reimbursement fee and out-of-pocket expense in the intervention group were all higher than those of the control group; these figures became lower than those of the control group after the intervention. Compensation ratio, length of stay, and readmission rate presented opposite changes. In terms of inpatient distribution, the number of township health centre visits in both counties dropped to about $8 \%$, which equalled the increase in visits to the county hospital. 
Table 2. Basic characteristics of inpatients in Xi and Huaibin Counties, 2011 and 2013.

\begin{tabular}{|c|c|c|c|c|c|c|}
\hline & \multicolumn{3}{|c|}{ Baseline (2011) } & \multicolumn{3}{|c|}{ Follow-Up (2013) } \\
\hline & Xi (Intervention) & Huaibin (Control) & $p$ & Xi (Intervention) & Huaibin (Control) & $p$ \\
\hline$N$ & 36,104 & 33,073 & & 59,087 & 51,325 & \\
\hline Gender & & & $<0.001$ & & & $<0.001$ \\
\hline Male & $15,173(42.03 \%)$ & $14,270(43.15 \%)$ & & $25,816(43.69 \%)$ & $21,577(42.04 \%)$ & \\
\hline Female & $20,931(57.97 \%)$ & $18,803(56.85 \%)$ & & $33,271(56.31 \%)$ & $29,748(57.96 \%)$ & \\
\hline Age group & & & $<0.001$ & & & $<0.001$ \\
\hline $0-17$ & $4897(13.56 \%)$ & $2944(8.90 \%)$ & & $6630(11.22 \%)$ & $3887(7.57 \%)$ & \\
\hline $18-34$ & $9973(27.62 \%)$ & $6605(19.97 \%)$ & & $12,711(21.51 \%)$ & $11,388(22.19 \%)$ & \\
\hline $35-64$ & $13,477(37.33 \%)$ & $15,554(47.03 \%)$ & & $23,820(40.31 \%)$ & $23,078(44.96 \%)$ & \\
\hline$\geq 65$ & $7757(21.49 \%)$ & $7970(24.09 \%)$ & & $15,926(26.95 \%)$ & $12,972(25.27 \%)$ & \\
\hline Institution level & & & $<0.001$ & & & $<0.001$ \\
\hline Township level & $17,921(49.64 \%)$ & $19,179(57.99 \%)$ & & $24,788(41.95 \%)$ & $25,212(49.12 \%)$ & \\
\hline County level & $18,183(50.36 \%)$ & $13,894(42.01 \%)$ & & $34,299(58.05 \%)$ & $26,113(50.88 \%)$ & \\
\hline Total spending (¥) & 2451.26 & 2103.90 & $<0.001$ & 2690.09 & 3066.93 & $<0.001$ \\
\hline Reimbursement fee (¥) & 1302.53 & 1264.99 & $<0.001$ & 1841.45 & 1898.87 & $<0.001$ \\
\hline Out-of-pocket expense (¥) & 1148.73 & 838.91 & $<0.001$ & 848.65 & 1168.06 & $<0.001$ \\
\hline Compensation ratio $(\%)$ & 54.27 & 59.17 & $<0.001$ & 69.46 & 59.18 & $<0.001$ \\
\hline Length of stay (days) & 7.05 & 7.71 & 0.558 & 9.43 & 7.85 & $<0.001$ \\
\hline Readmission & & & $<0.001$ & & & $<0.001$ \\
\hline No & $35,006(96.96 \%)$ & $31,492(95.22 \%)$ & & $55,853(94.53 \%)$ & $48,804(95.09 \%)$ & \\
\hline Yes & $1098(3.04 \%)$ & $1581(4.78 \%)$ & & $3234(5.47 \%)$ & $2521(4.91 \%)$ & \\
\hline
\end{tabular}

The symbol ¥ represents Chinese yuan.

\subsection{Policy Effects Shown by Observing Smooth Curve Trend}

At the whole-county level, the intervention of upgraded case payment resulted in evident changes among the independent variables of the intervention group (Figure 2). Unlike the continuous increase in the control group, the total spending of the intervention group showed a stable trend; the reimbursement fee of both groups increased, but the ascensional range of the intervention group was lower than that of the control group. The out-of-pocket expenses of the control group fluctuated, whereas those of the intervention group showed a considerable decline and then stabilised. The compensation ratio manifested an opposite trend. In terms of length of stay, the smoothing spline of the control group did not change distinctly, whereas that of the intervention group experienced a rapid growth in the first year and then stabilised. No major change in readmission rate was observed in the control group, whereas that of the intervention group was higher than that of the control group in 2013 after a considerable increase.

At the county hospital level, the changing trends of independent variables in intervention group were similar to those of the whole county level except for reimbursement fee, which grew consecutively and rapidly over the analysis period (Figure 3). The length of stay of the control group decreased markedly after a slight rise. At the baseline, the total spending, reimbursement fee and out-of-pocket expense values of the intervention group were higher than those of the control group but became lower than those of the control group after two years of policy implementation; the values of compensation ratio and length of stay showed opposite changes. The overall trends of readmission rate in both counties increased; although the readmission rate of the intervention group was visibly lower than that of the control group initially and showed a slight decline, it became close to that of the control group after a considerable growth.

At the township health centre level, the cost-related indicators in intervention group all showed a decline trend (Figure 4). Total spending and out-of-pocket expense decreased steadily, and although reimbursement fee fluctuated, its reduction was greater than its growth. The changes of these trends in the control group were similar to that of the whole county and county hospital levels. The policy caused the compensation ratio of the intervention group to increase continually, and the length of stay declined after a considerable growth. Unlike the change of readmission rate of the control group, that of the intervention group rebounded after a decline. 

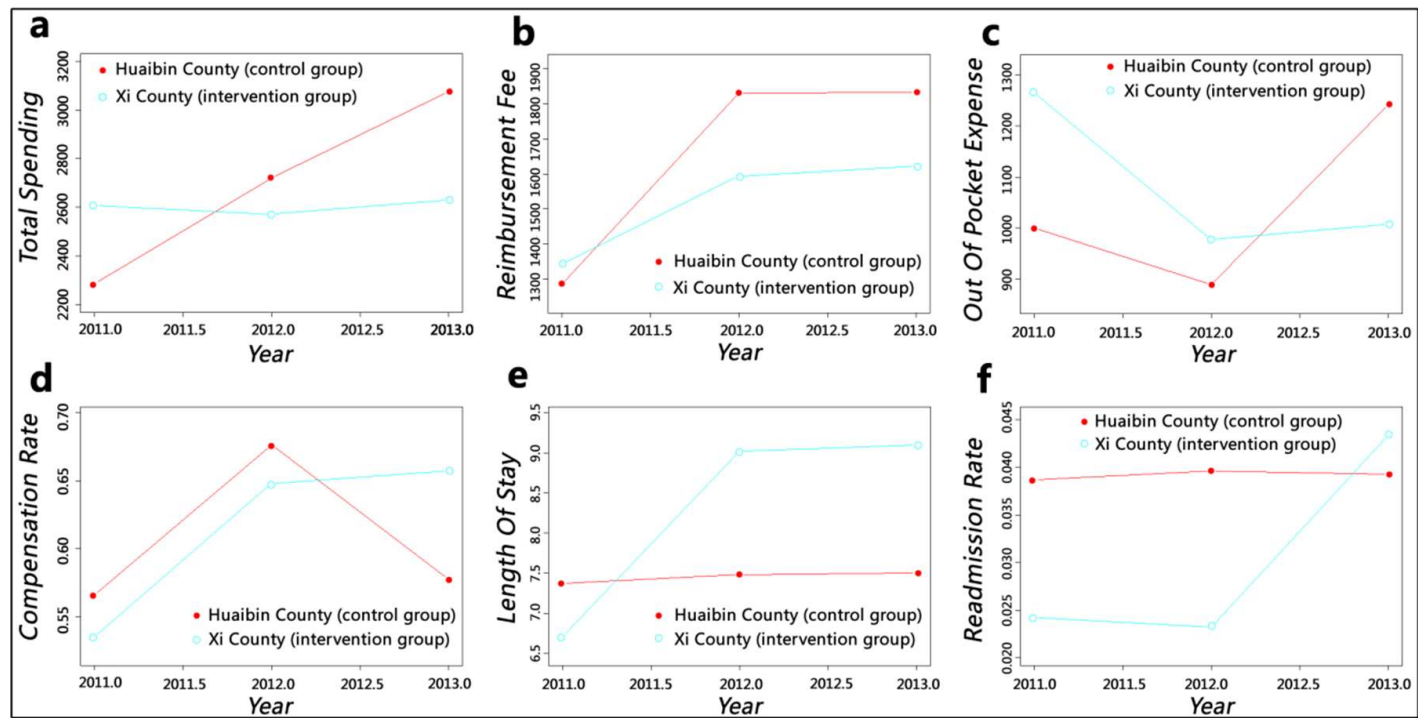

Figure 2. Smooth curves fitting for the whole county level: (a) adjusted mean of total spending; (b) adjusted mean of reimbursement fee; (c) adjusted mean of out-of-pocket expense; (d) adjusted mean of compensation ratio; (e) adjusted mean of length of stay; (f) adjusted mean of readmission rate.
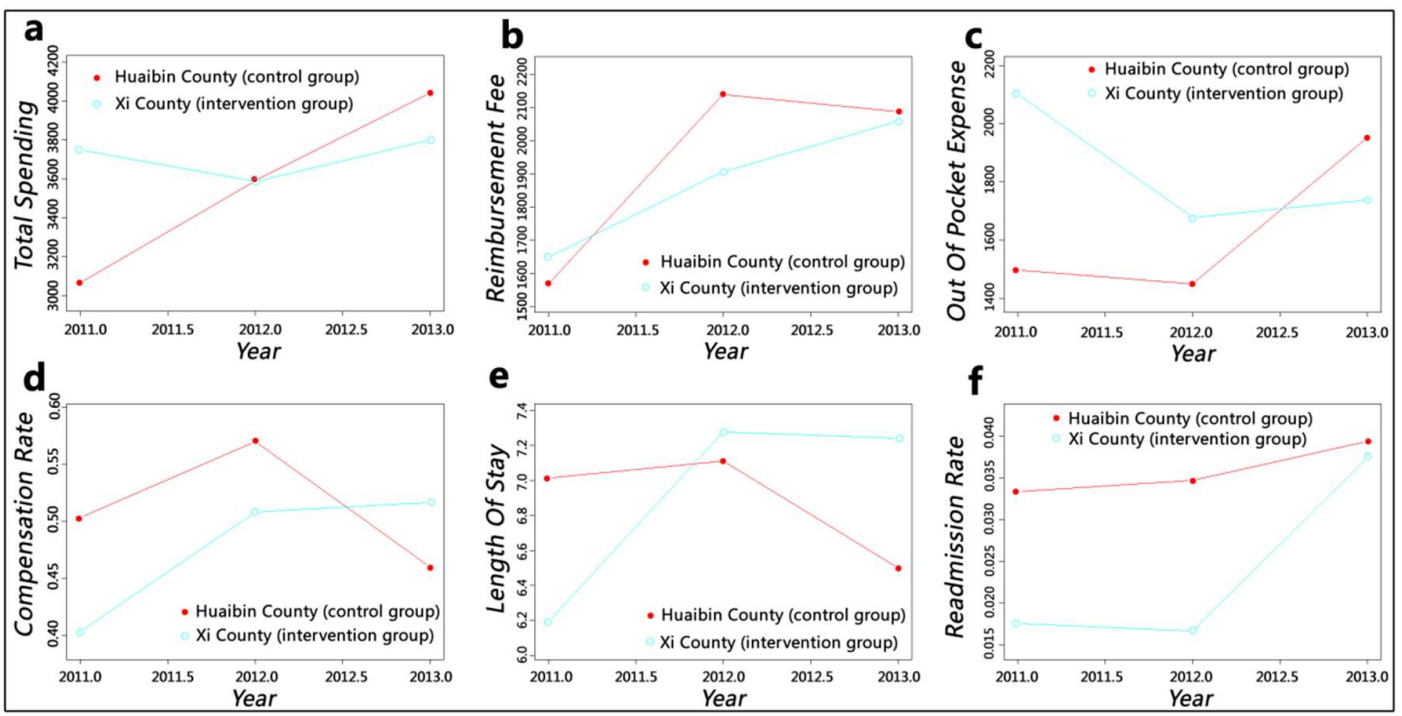

Figure 3. Smooth curves fitting for the county hospital level: (a) adjusted mean of total spending; (b) adjusted mean of reimbursement fee; (c) adjusted mean of out-of-pocket expense; (d) adjusted mean of compensation ratio; (e) adjusted mean of length of stay; (f) adjusted mean of readmission rate. 

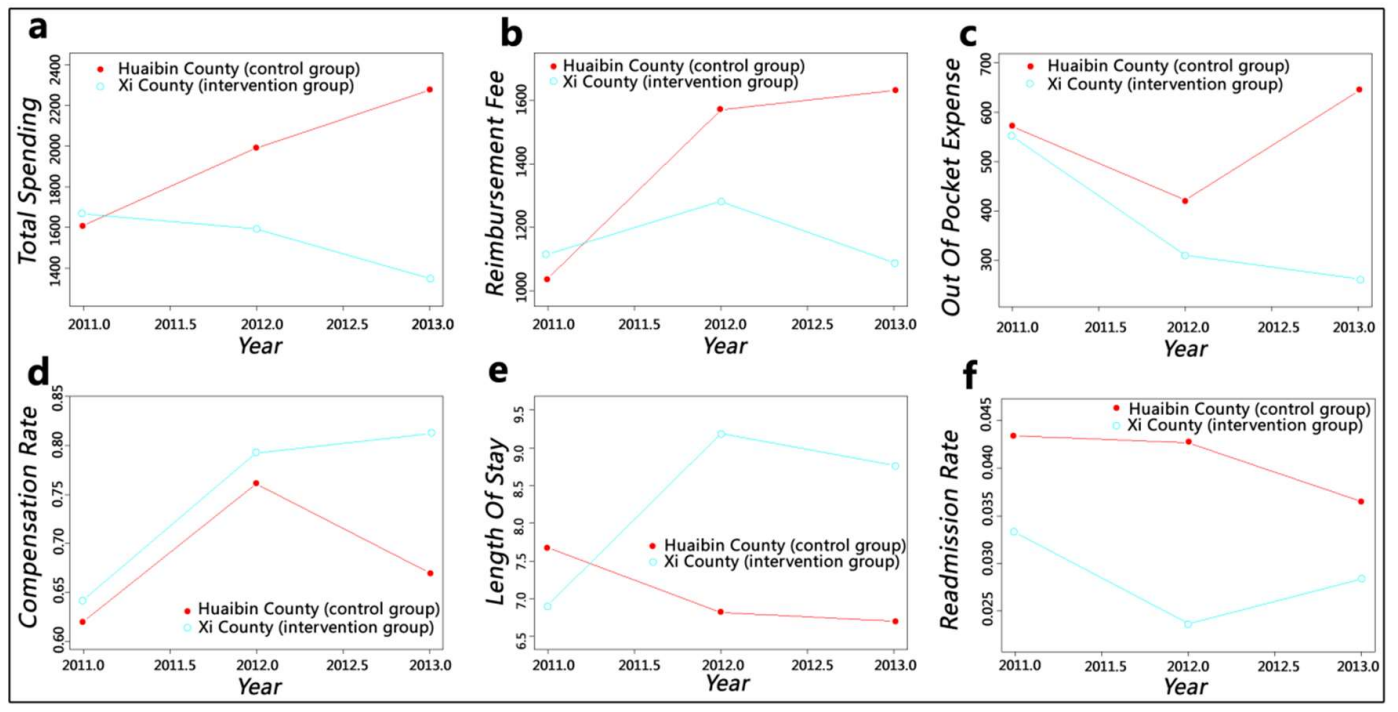

Figure 4. Smooth curves fitting for the township health centre level: (a) adjusted mean of total spending; (b) adjusted mean of reimbursement fee; (c) adjusted mean of out-of-pocket expense; (d) adjusted mean of compensation ratio; (e) adjusted mean of length of stay; (f) adjusted mean of readmission rate.

\subsection{Policy Effects Observed from Difference-In-Differences Approach (DID) Model Outcomes}

The estimation at the whole-county level showed the effectiveness of cost control (Table 3): the total spending per capita decreased by $¥ 346.59(p<0.001)$, which amounted to a $21.63 \%$ decline. The contribution of out-of-pocket expense (reduction of $¥ 241.2 p<0.001$ ) was higher than that of reimbursement fee (¥105.39, $p<0.001)$. Therefore, compensation ratio increased by $7 \%(p<0.001)$. However, the ungraded case payment reform led to an increase in length of stay and readmission rate by 2.18 days $(p<0.001)$ and $1.5 \%(p<0.001)$, respectively.

The impact of cost control on total spending at the county hospital level was more apparent, with a reduction of $¥ 943.14$ or a $57.88 \%$ decline. The reduction of reimbursement fee was slightly higher than that of the whole-county level, which was $¥ 150.16(p<0.001)$; the out-of-pocket expense faced the largest decline of $¥ 792.97(p<0.001)$, which was much greater than that of the whole county and township health centre levels. Compensation ratio increased the most with $14.4 \%(p<0.001)$. The length of stay and readmission rate at the county hospital level also increased by 1.24 days $(p<0.001)$ and $3.3 \%(p<0.001)$, respectively.

Total spending and reimbursement fee had the biggest drop of $¥ 1220.55(p<0.001)$ and $¥ 818.22$ $(p<0.001)$ at the township health centre level. The change in out-of-pocket expense was significant but lower than that of the county hospital level, with a decline of $¥ 402.34(p<0.001)$. Compensation ratio also increased by $13.7 \%(p<0.001)$. Length of stay had the largest increase of 4.45 days $(p<0.001)$, and readmission rate showed an insignificant reduction of $0.5 \%(p=0.185)$. This result may be due to the fact that the increase of readmission rate at the whole-county level was caused by county hospitals. 
Table 3. Results of difference-in-differences analysis on policy effects.

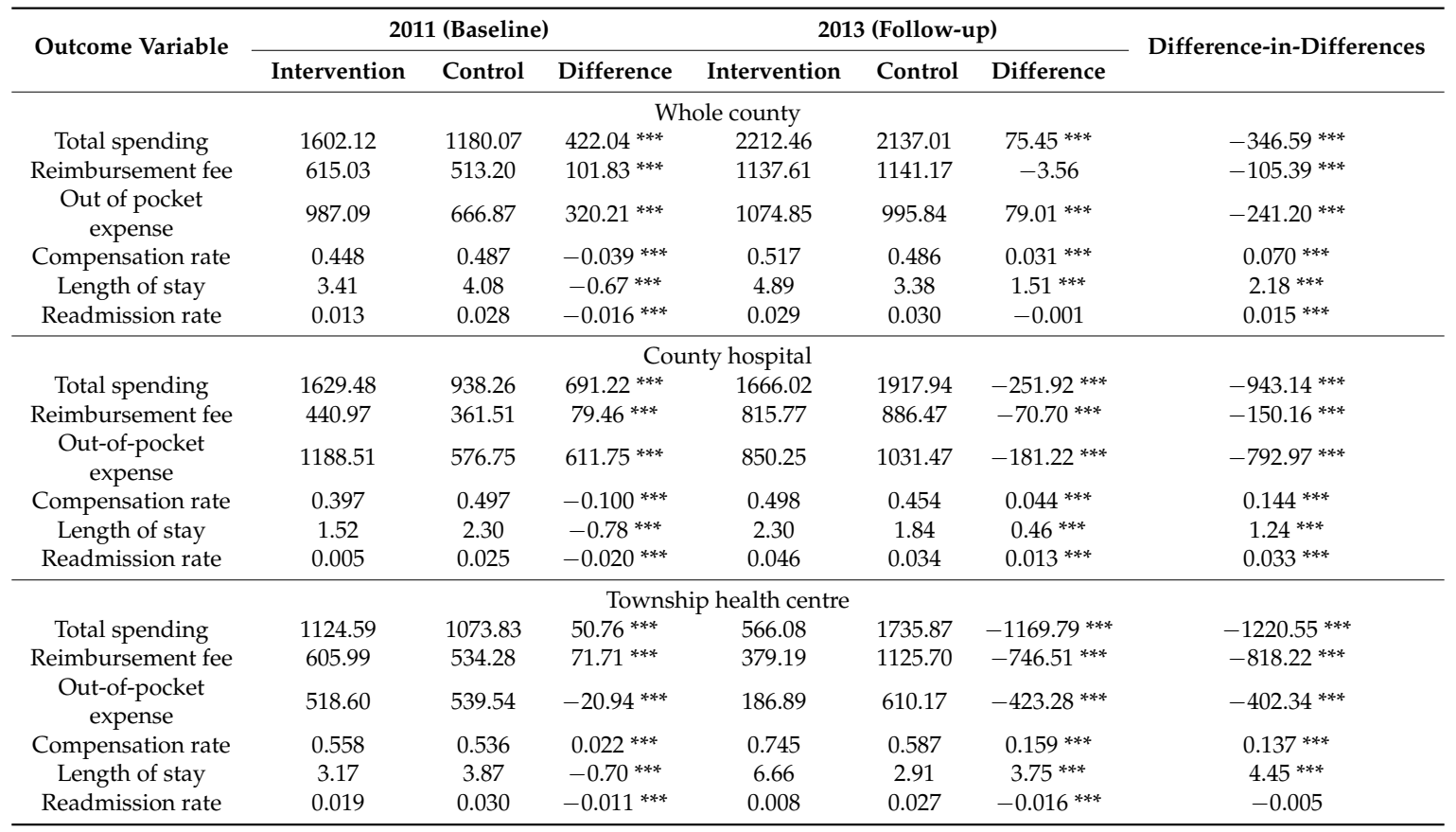

Adjusted results are from a difference-in-differences model controlling for all covariates. ${ }^{* * *} p<0.001$.

\section{Discussion}

GAMs can intuitively describe the changing trends of the outcome variables during the intervention period, and the DID model can accurately reflect the changing values of the outcome variables. Therefore, we believe that the combination of these two methods can be used to evaluate the effects of a policy comprehensively and rationally.

If we merely focus on the cost control dimension, then our analysis shows encouraging results: the total spending at the whole county and county hospital levels showed a fluctuating but not rising trend and an obvious decline at the township hospital level (from smooth curves); the reduction degrees were $21.63 \%, 57.88 \%$, and $108.53 \%$ at the whole county, county hospital, and township health centre levels, respectively (from DID estimation). However, our findings were inconsistent with two previous studies that also focused on Xi County payment reform; they believed that the reform failed to curb the cost growth, and total spending per capita continued to increase $[21,28]$. Three reasons were given for this conflict: Firstly, their research chose only one disease (caesarean section or chronic obstructive pulmonary disease), which cannot reflect and represent the impacts on the entire county. Secondly, they merely analysed the changes of intervention objects before and after the reform, and they lacked a suitable control group and did not control the time effects. Thus, the conclusions were not convincing. Thirdly, to successfully implement the reform at the starting period, some diseases' profit margins were not reduced. However, the reform indeed cut off the direct link between cost and revenue.

With the enhancement of insurance funding, the annual premium per enrolee for the New Cooperative Medical Scheme was raised from $¥ 30$ in 2003 to $¥ 570$ in 2014 . We can speculate that reimbursement fee should show an upward trend but still cannot keep up with the rising speed of expenditures, which caused an imbalance in the funding pool [43,44]. Figures 2 and 3 show this trend; the growth range of the intervention group was lower than that of the control group. Moreover, reimbursement fee at the township level of the intervention group decreased after one year of policy implementation. Compensation ratio can reflect the efficiency of insurance fund utilisation. This value of the control group fluctuated to keep the funds balanced; although intervention group slowed down the increasing speed after a sharp growth at first year, it still kept rising. The compensation ratio of the whole county level increased by $7 \%$, and the county and township levels increased by more 
than $10 \%$. Therefore, the reform has effectively alleviated the pressure on medical insurance funds and improved the efficiency of its utilisation considerably. However, insurance funds flowed heavily into county hospitals, as indicated by a comparison of the findings at the county and township levels. This phenomenon could further widen the gap in service capacity between counties and towns and pose challenges to the development of township health centres.

The value of out-of-pocket expense can indicate patients' economic burden of disease and shows an increasing trend with the rapid growth of health expenditures. Despite fluctuations, the out-of-pocket expense of the control group increased continually, whereas the out-of-pocket expense at the whole-county and county hospital levels of the intervention group showed a considerable downward trend even when it increased slightly in the second year. The out-of-pocket expense at the township health centre level declined steadily. The DID results were consistent with the GAMs: The county hospital had the largest reduction of $¥ 792.97$, and the township health centre also dropped by $¥ 402.34$. The reform has effectively alleviated inpatients’ economic burden in Xi County. However, this situation may lead to a hidden danger: aggravation of the previously mentioned issue of irrational medical service utilisation, which showed that patients tend to seek higher-level medical institution's services instead of what they actually need. County hospitals have solved numerous diseases under township health centres' service capacity [45], thereby increasing their bed occupancy rate to greater than $100 \%$ [46]. The reform has made the absolute value of the decline of the out-of-pocket expense in county hospitals much larger than that of the township health centre, which would cause patients to perceive that "hospitalisation services are much cheaper in county hospitals" and could simulate them to rely more on county hospital services.

Whether in rural or urban areas, medical institutions, especially high-level hospitals, are trying to shorten length of stay as much as possible and increase bed turnover to gain more benefits. The analysis results for the control group confirm this phenomenon. However, after the implementation of the upgraded case payment reform, the length of stay of the intervention group increased by 2.18 days, and the growth at the township level was higher than that at the county level. This phenomenon may be caused by the implementation of clinical pathways: physicians cannot decide patients' discharge according to their clinical experience anymore. Rather, they must provide standard services every day based on the clinical path regulations, and they must consent to discharge only when the patients' clinical condition meets the discharging indications within the specified time. Doing otherwise will be considered a violation, thereby affecting the compensation amount they receive.

Although the length of stay of the intervention group manifested a rising trend, we cannot conclude that the service efficiency was reduced, which should combine the changes of quality. The county-level readmission rate of the control group showed no obvious change, whereas that of the intervention group increased significantly. This result may be caused by decomposing hospitalisation, which is a disguised trick of medical institutions who aimed to obtain more insurance compensation [16]. Therefore, we can presume that the reform had not improved service quality and played no positive impact on service efficiency in the county. A similar situation was observed at the county hospital, and the growth range of readmission rate was greater. This issue needs to be taken seriously by insurance agencies, and the occurrence of readmissions should be reviewed strictly. This trend of the intervention group at the township level fluctuated and finally reached an insignificant decrease. We believed that the reform (mainly clinical pathway) had improved the service quality of township health centres and the growth of length of stay could not be simply ascribed to decreased efficiency. However, due to the previously mentioned issues which arise from changes in reimbursement fee and length of stay, the prospects of township health centres are not optimistic.

\section{Limitations}

Our study has several limitations. Firstly, we selected only one county as the intervention group and one county as the control group; both counties are located in one province. Thus, our results may not be generalisable to other counties in rural China. However, the reform in Xi County is 
representative across the country, and many counties have begun to follow suit. In the context of national promotion of case payment, our research offers reference value for other counties. Secondly, our analysis period lasted from 2011 to 2013 only because of the payment reform in the control group. Finding a county that maintains a unified payment method for a long time is difficult because the vast majority of regions in China are exploring payment reform. Meanwhile, study results confirmed the effectiveness of cost control of the upgraded case payment model and discovered some potentially hidden dangers that will guide future reform. Thirdly, although the reform is aimed at inpatient services, the study can perform a more comprehensive evaluation if it determines whether the reform leads to service transfer to outpatient, which is a subject of concern for future studies.

\section{Conclusions}

In general, the upgraded case payment reform successfully curbs the growth of medical expenses, improves the efficiency of medical insurance fund utilisation and alleviates patients' economic burden of disease. Considering the complexity of the disease makes the payment design reasonable, and applying the clinical pathway improves the accuracy of cost calculation and can regulate and guide medical services. This payment reform provides a good inspiration for regions where DRGs are unavailable, especially in rural areas. A detail that should be noted is that the reform did not play a positive role in service quality and efficiency at the whole-county level. Moreover, the increase in readmission rate is an urgent problem that needs to be solved by health administration and medical insurance departments. In addition, the reform has resulted in insurance expenses being directed to county hospitals and may cause patients to opt for treatments at county hospitals. These phenomena go against the long-term development of primary healthcare institutions. Future payment reform should pay more attention to the health service delivery system, particularly with respect to cost, quality, and efficiency.

Author Contributions: R.H. analysed data and drafted the manuscript. Y.N. and Z.L. collected data and modified the manuscript. T.Y., Y.Z., and J.W. checked the language and modified the manuscript. L.Z. negotiated with local health department and gave guidance on study design. All authors read and approved the final manuscript.

Funding: This research was funded by National Natural Science Foundation of China (NSFC), Contract No. 71673099/G0308.

Acknowledgments: We would like to thank the staff of health management department and health insurance department of Xi County and Huaibin county for their support on the research. We also want to thank the associate editor and reviewers for their careful review and insightful comments which have led to significant improvement of the manuscript.

Conflicts of Interest: The authors declare no conflict of interest.

\section{References}

1. Keehan, S.P.; Cuckler, G.A.; Sisko, A.M.; Madison, A.J.; Smith, S.D.; Stone, D.A.; Poisal, J.A.; Wolfe, C.J.; Lizonitz, J.M. National health expenditure projections, 2014-24: Spending growth faster than recent trends. Health Aff. 2015, 34, 1407-1417. [CrossRef] [PubMed]

2. OECD. Health at a Glance 2017: OECD Indicators. 2017. Available online: http://dx.doi.org/10.1787/ health_glance-2017-en (accessed on 10 November 2017).

3. National Health and Family Planning Commission of the People's Republic of China. China Health Statistical Yearbook 2017. Available online: http:/ / www.yearbookchina.com/navibooklist-n2017120225-1. html (accessed on 1 September 2017). (In Chinese)

4. Eggleston, K. Kan Bing Nan, Kan Bing Gui: Challenges for China's Healthcare System Thirty Years into Reform; Walter, H. Shorenstein Asia-Pacific Research Center: Stanford, CA, USA, 2010.

5. Zhao, C.R.; Wang, C.; Shen, C.W.; Wang, Q. Diagnosis-related group (DRG)-based case-mix funding system, a promising alternative for fee for service payment in China. Biosci. Trends 2018, 12, 109-115. [CrossRef] [PubMed]

6. Busse, R.; Schreyögg, J.; Smith, P.C. Hospital case payment systems in Europe. Health Care Manag. Sci. 2006, 9, 211-213. [CrossRef] [PubMed] 
7. Hwang, C.J.; See, L.C.; Chuang, Y.C. Case Payment and the Adoption of New Technology: An Empirical Study of Cataract Surgery in Taiwan. Chang Gung Med. J. 2004, 27, 327-336. [PubMed]

8. Salkever, D.S.; Steinwachs, D.M.; Rupp, A. Hospital cost and efficiency under per service and per case payment in Maryland: A tale of the carrot and the stick. Inquiry 1986, 23, 56-66. [PubMed]

9. Cheng, Y.L.; Chen, Y.C. Application Research of the Clinical Pathway in Single Disease Payment. Med. Soc. 2012, 25, 50-52. (In Chinese)

10. Tan, Y.Q.; Xiang, L.; Xiong, J.Y.; Chen, Y.; Yao, L. A study on the limiting expenses payment of a single disease in Qianjiang district Chongqing city. Chin. J. Health Policy 2009, 2, 14-17. (In Chinese)

11. Lang, H.C.; Chi, C.; Liu, C.M. Impact of the case payment reimbursement method on the utilization and costs of laparoscopic cholecystectomy. Health Policy 2004, 67, 195-206. [CrossRef]

12. Quinn, K. After the revolution: DRGs at age 30. Ann. Intern. Med. 2014, 160, 426-429. [CrossRef]

13. Reid, B.; Palmer, G.; Aisbett, C. The performance of Australian DRGs. Aust. Health Rev. 2000, $23,20-31$. [CrossRef]

14. Okamura, S.; Kobayashi, R.; Sakamaki, T. Case-mix payment in Japanese medical care. Health Policy 2005, 74, 282-286. [CrossRef] [PubMed]

15. Chen, Y.Y.; Xu, X.H.; Liu, G.M.; Xiang, G.P. Brief introduction of medical insurance system in China. Asia Pac. J. Oncol. Nurs. 2016, 3, 51. [CrossRef] [PubMed]

16. He, R.B.; Miao, Y.D.; Ye, T.; Zhang, Y.; Tang, W.X.; Zhang, L. The effects of global budget on cost control and readmission in rural China: A difference-in-difference analysis. J. Med. Econ. 2017, 20, 903-910. [CrossRef] [PubMed]

17. National Health Commission of the People's Republic of China. Circular on the Pilot Work of Case Based Payment. 2004. Available online: http:/ /www.moh.gov.cn/mohghcws/s3582/200804/16422.shtml (accessed on 17 August 2004). (In Chinese)

18. National Development and Reform Commission. Circular on the Promoting the Case Based Payment. 2017. Available online: http:/ /www.ndrc.gov.cn/zcfb/zcfbtz/201701/t20170116_835180.html (accessed on 10 January 2017). (In Chinese)

19. General Office of the State Council. Guidance on Further Deepening the Reform of Basic Medical Insurance Payment. 2017. Available online: http://www.gov.cn/zhengce/content/2017-06/28/content_5206315.htm (accessed on 28 June 2017). (In Chinese)

20. Jin, P.Y.; Biller-Andorno, N.; Wild, V. Ethical Implications of Case-Based Payment in China: A Systematic Analysis. Dev. World Bioeth. 2015, 15, 134-142. [CrossRef] [PubMed]

21. Liu, S.; Wang, J.; Zhang, L.; Zhang, X. Caesarean section rate and cost control effectiveness of case payment reform in the new cooperative medical scheme for delivery: Evidence from Xi County, China. BMC Pregnancy Childbirth 2018, 18, 66. [CrossRef] [PubMed]

22. Liu, J.Z.; Liu, G.X.; Gao, X.; Lv, L.L. Research on the Implementation of Single-DRGs Reform under Chinese New Rural Cooperative Medical System. Chin. Health Econ. 2013, 32, 47-49. (In Chinese)

23. Xie, L.; Wang, H.P.; Zhou, L.L.; Zhong, X.X.; Ding, H. Analysis on the composition and influencing factors of coronary heart disease patients' hospitalization expenses under DRGs in Anhui Province. Chin. J. Health Policy 2018, 11, 70-73. (In Chinese)

24. Jin, P.Y.; Biller-Andorno, N.; Wild, V. Case-Based Payment System in the Chinese Healthcare Sector and Its Ethical Tensions. Asian Bioeth. Rev. 2013, 5, 131-146.

25. Cheng, N.; Wang, Z.L.; Fu, X.G.; Song, D.P.; Ren, J.; Zhao, D.H. Analysis on the Results of Medical Expense Control and Influencing Factors in Typical Regions of Payment Reforms under New Rural Cooperative Medical System. Chin. Health Econ. 2017, 36, 32-35. (In Chinese)

26. Li, Y.; Yang, W.; He, R.B.; Zhang, L. Thoughts and Practice of DRGs-Based Multi-Faceted Payment Reform in Xixian, Henan Province. Chin. Health Econ. 2017, 36, 36-38. (In Chinese)

27. Shi, L.Y.; Makinen, M.; Lee, D.C.; Kidane, R.; Blanchet, N.; Liang, H.; Li, J.; Lindelow, M.; Wang, H.; $\mathrm{Xie}, \mathrm{S}$;; et al. Integrated care delivery and health care seeking by chronically-ill patients-A case-control study of rural Henan province, China. Int. J. Equity Health 2015, 14, 98. [CrossRef] [PubMed]

28. Shi, M.; Wang, J.; Zhang, L.; Yan, Y.; Miao, Y.D.; Zhang, X. Effects of Integrated Case Payment on Medical Expenditure and Readmission of Inpatients with Chronic Obstructive Pulmonary Disease: A Nonrandomized, Comparative Study in Xi County, China. Curr. Med. Sci. 2018, 38, 558-566. [CrossRef] [PubMed] 
29. The World Bank. China-Rural Health Project. 2008. Available online: http://projects.worldbank.org/ P084437/rural-health-project?lang=en (accessed on 24 December 2014).

30. Sheynin, O.B. Studies in the history of probability and statistics. XXI. On the early history of the law of large numbers. Biometrika 1968, 5, 59-67. [CrossRef]

31. Yip, W.C.; Wang, H.; Liu, Y. Determinants of patient choice of medical provider: A case study in rural China. Health Policy Plan. 1998, 13, 311-322. [CrossRef] [PubMed]

32. Guo, M.T.; Wu, Q.H.; Li, Y.; Hao, Y.H.; Huang, Z.Q.; Jiao, M.L.; Liang, L.B.; Kang, Z. Analysis of the Change Tendency of Inpatient Flow and Hospital Cost Burden Among Rural Residents Under New Rural Cooperative Medical Scheme. Chin. Hosp. Manag. 2015, 35, 72-74. (In Chinese)

33. Yang, Y.; Ning, J.G.; Zhao, J.; Xiong, L.P. Analyzing the status of hospitalization of insured in the New Rural Cooperative Medical System in different medical institutions. Chin. Health Serv. Manag. 2015, 32, 135-137. (In Chinese)

34. Jin, T.J.; Chen, Y.C.; Wu, N.N.; Zhang, L.J.; Li, H.M.; Shi, L.Q.; Zhang, Y. Analysis on the Effects of the Adjusting the Hospitalized Distribution of Patients outside the County on the New Rural Cooperative Medical System Fund and the Resident Compensation Beneficiary: Taking a County of Hubei as Case Study. Chin. Health Econ. 2015, 34, 36-39. (In Chinese)

35. DiMatteo, M.R.; Sherbourne, C.D.; Hays, R.D.; Ordway, L.; Kravitz, R.L.; McGlynn, E.A.; Kaplan, S.; Rogers, W.H. Physicians' characteristics influence patients' adherence to medical treatment: Results from the Medical Outcomes Study. Health Psychol. 1993, 12, 93. [CrossRef]

36. Zhang, Y.T.; Ma, Q.H.; Chen, Y.C.; Gao, H.X. Effects of public hospital reform on inpatient expenditures in rural China. Health Econ. 2017, 26, 421-430. [CrossRef]

37. Abadie, A. Semiparametric difference-in-differences estimators. Rev. Econ. Stud. 2005, 72, 1-19. [CrossRef]

38. Hastie, T.; Tibshirani, R. Generalized Additive Models. Stat. Sci. 1986, 1, 297-310. [CrossRef]

39. Guisan, A.; Edwards, T.C., Jr.; Hastie, T. Generalized linear and generalized additive models in studies of species distributions: Setting the scene. Ecol. Model. 2002, 157, 89-100. [CrossRef]

40. Li, H.M.; Chen, Y.C.; Gao, H.X.; Zhang, Y.; Chen, L.; Chang, J.J.; Su, D.; Lei, S.H.; Jiang, D.; Hu, X.M. Effectiveness evaluation of quota payment for specific diseases under global budget: A typical provider payment system reform in rural China. BMC Health Serv. Res. 2018, 18, 635. [CrossRef] [PubMed]

41. Ke, H.; Ma, J.; Zhang, F. The Application of Generalize Additive Models in Medical Cost Control. Chin. J. Health Stat. 2012, 29, 833-836. (In Chinese)

42. National Bureau of Statistics of the People's Republic of China. China Statistical Yearbook. 2014. Available online: http:/ / data.stats.gov.cn/easyquery.htm?cn=C01\&zb=A090305\&sj=2017 (accessed on 1 September 2014).

43. Ding, R.; Ji, J.P.; Gao, G.Y.; Zhang, Y.; Liu, S.P. Reflecting on the Factors Contributing to the Fund Overspending of the Cooperative Medical Scheme in Beijing and the Solutions to the Problem. Chin. Health Econ. 2012, 31, 38-40. (In Chinese)

44. Ren, G.; Wang, Z.L. Empirical Analysis of the Reasons for Fund Cost Overruns of the New Rural Cooperative Medical Scheme. Chin. Health Econ. 2012, 31, 43-45. (In Chinese)

45. Li, Z.; Yang, J.; Wu, Y.; Pan, Z.J.; He, X.Q.; Zhang, L. Challenges for the surgical capacity building of township hospitals among the Central China: A retrospective study. Int. J. Equity Health 2018, 17, 55. [CrossRef]

46. Ji, X.R.; Wang, L.S. Analysis on Bed Utilizition Rate of County Level Hospitals in Central and Western Region. Chin. Health Econ. 2010, 29, 21-24. (In Chinese)

(C) 2018 by the authors. Licensee MDPI, Basel, Switzerland. This article is an open access article distributed under the terms and conditions of the Creative Commons Attribution (CC BY) license (http:/ / creativecommons.org/licenses/by/4.0/). 